\title{
Mapping the Supply Chain Issues SMEs and Impact for Quality Products
}

\author{
Ayi Tejaningrum, Anton Mulyono Azis, Maya Irjayanti \\ Stie Ekuitas, Bandung, Indonesia
}

\begin{abstract}
Until now, the issue of quality of the products of SMEs (small and medium enterprises) remains the main issues as the cause of low ability to compete. This study focused into the issue of what happened with regard to the quality of products in the supply chain SME products. This study aims to describe how the culture of quality in the supply chain of SMEs and their role in contributing to the lack of SME products. The study involved 128 SMEs in the food processing industry cluster and garment industry. The research uses qualitative method with case study approach. The results showed an average internal quality culture reached 3.62661 supply included in the category enough. Of the five industry cluster, a culture of quality in the internal supply chain is the best T-shirt industry (4.3385) in both categories, while other four clusters exist in enough categories, with grades: hoods (3.661), soy crisps (3.6635), cassava chips (3.64), and the last chips fish balls (2.829). The low average internal quality culture supply mainly is in industrial processing of cassava chips and chips fish balls. One reason is the low awareness of quality. There is no technology and equipment adequate to safeguard the stability of quality. The upper most excellent quality culture occurred in the supply chain, where the product is controlled by big industry, is the industry shirts (4.018), soy crisps (3.613), and hoods (3.473), while when in the upstream industry controlled by small or SMEs, there is deterioration in the cultural values of quality: cassava chips (2.917) and chips fish balls (2.781). For downstream, $100 \%$ controlled by SMEs, there is an average value of quality culture 3.5662 .
\end{abstract}

Keywords: supply chain, upstream, downstream, a culture of quality, small and medium enterprises (SMEs)

\section{Introduction}

Supply chain plays an important role in improving the company's ability to maintain customer satisfaction both from the aspect of timeliness and quality aspects of goods and services. This study examines how the role of supply chain is in the process of maintaining product quality, especially at small and medium enterprises (SMEs). Tejaningrum (2014) showed that one of the problems in SMEs is the inconsistency of product quality, and consistent quality of products is related to the significance of customer loyalty.

The quality of products and services is one of the determining factors in the company's success in winning business competition. Diverse researches say that the quality of products and services produced is closely related to the company's ability to survive in the competitive landscape increasingly tight business and weight.

Ayi Tejaningrum, Ph.D., Management Department, Stie Ekuitas, Bandung, Indonesia.

Anton Mulyono Azis, Ph.D., Management Departement, Stie Ekuitas, Bandung, Indonesia.

Maya Irjayanti, Management Departement, Stie Ekuitas, Bandung, Indonesia.

Correspondence concerning this article should be addressed to Ayi Tejaningrum, PHH Mustopa No. 31, Bandung, Indonesia.

E-mail: ayitejaningrum@yahoo.com. 
Tejaningrum and Anton Azis (2015) mentioned that some of the benefits if the company is able to produce quality products are: (1) reducing customer complaints; (2) reducing scrap; (3) increasing consumer confidence; (4) increasing profitability and market share; (5) the higher the confidence of stakeholders; etc.

Product quality will be achieved well in the company when the collective agreement occurred among the member companies either in writing or not respecting the habits, values, beliefs, and perceptions about the preservation stability of product quality, or referring to a culture of quality. The final result of product quality goods and services which received final consumer is a combination of quality culture produced by subcontractors/supplier/distributor engaged in a series of supply chain, from upstream to downstream.

This study aims to analyze the culture of quality in the supply chain culinary industry and clothing SMEs, both in the internal supply as well as upstream and downstream. The study was conducted at three centers and two central food industry clothing industries in West Java, Indonesia, involving 128 SMEs from upstream to downstream.

\section{Theoretical Review}

\section{Supply Chain}

Supply chain is a logistic concept of sustainability of the company. The role of supply chain management is becoming increasingly important as the products produced by the company involve a lot of supplier or distributor upstream. The process of implementation of the supply chain will involve parts ordering, distribution, and production. Into three parts, this requires a higher role in the appeal of the other functions like financial and human resources.

Some definitions include supply chain. Pujawan (2005) emphasized the network of cooperation among companies to deliver products to consumers. Heizer and Render (2010) emphasized the activity of procurement of raw materials, services, and transformation into semi-finished goods as well as the final product which reaches the consumer. Tejaningrum (2013) is a business structure from upstream to downstream, involving all the suppliers and distributors for the process of delivering the final product to the consumer.

Some researches have been done with regard to the effectiveness of the supply chain. Zhao, Cornelia, and Theodore (2001) stated that the effectiveness of the supply chain has to be assessed on how much the ability of distributors, suppliers, and all components of the supply chain gives satisfaction to the consumer. Narasimhan and Kim (2001) emphasized the utility of information in support of supply chain reliability, because another one requires fast and accurate coordination. Thomas and Griffin (1996) said that supply chain in the process should be able to lower costs by doing an accurate coordination among the three major parts of the distribution function, the function of procurement, and production functions.

In analyzing the chain of supply chain, it must be seen as a comprehensive unity, from upstream to downstream until the product to the consumer. Croxton, Garcia-Dastugue, Lambert, and Rogers (2001) emphasized the effectiveness of supply chain to the chain of processes from upstream to downstream. Lambert and Cooper (2000) insisted the importance of the role of marketing in the supply chain. Spillan, McGinnis, Kara, and Yi (2013) emphasized the effectiveness of coordination of logistics and customer service effectiveness and the effectiveness of an impact on the organization. Seuring and Sarkis (2008) mentioned that a supply chain must consider the social and environmental aspects. While Stank, Keller, and Daugherty (2001) said that the collaboration among the external supply chain impacts the reliability of internal collaboration processes. The income is concluded in Table 1. 
Table 1

Resume Research Regarding the Effectiveness of Supply Chain

\begin{tabular}{|l|l|}
\hline Source & Effectiveness of supply chain \\
\hline Zhao, Cornelia, and Theodore (2001) & Customer-focused capabilities. \\
\hline Narasimhan and Kim (2001) & Information system utilization. \\
\hline Thomas and Griffin (1996) & $\begin{array}{l}\text { Reduction in operating costs through the supply chain coordination functions of } \\
\text { procurement, production, and distribution. }\end{array}$ \\
\hline Lambert and Cooper (2000) & Cross-functional integration and marketing must play a critical role. \\
\hline Croxton et al. (2001) & Approach processes in supply chain management. \\
\hline Spillian et al. (2013) & $\begin{array}{l}\text { When combined with logistics coordination effectiveness (LCE) and customer service } \\
\text { effectiveness (CSE), it contributes to organizational effectiveness (COMP). }\end{array}$ \\
\hline Seuring and Sarkis (2008) & $\begin{array}{l}\text { Social and environmental aspects should get the attention of every member of the } \\
\text { supply chain. }\end{array}$ \\
\hline Stank et al. (2001) & $\begin{array}{l}\text { Collaboration with external supply chain entities influences increased internal } \\
\text { collaboration, which in turn improves service performance. }\end{array}$ \\
\hline
\end{tabular}

\section{Quality Culture}

The concepts of quality culture, adopting what is presented by Tejaningrum and Anton Azis (2015), are namely: trust, action, thought patterns, values, habits, and thought, believed and owned by members of the organization. Beliefs and values are reflected in the decision making process, the behavior of human resources, environmental management, management of engineering and artifacts, as well as quality obsession. Models developed a culture of quality shown in Figure 1.

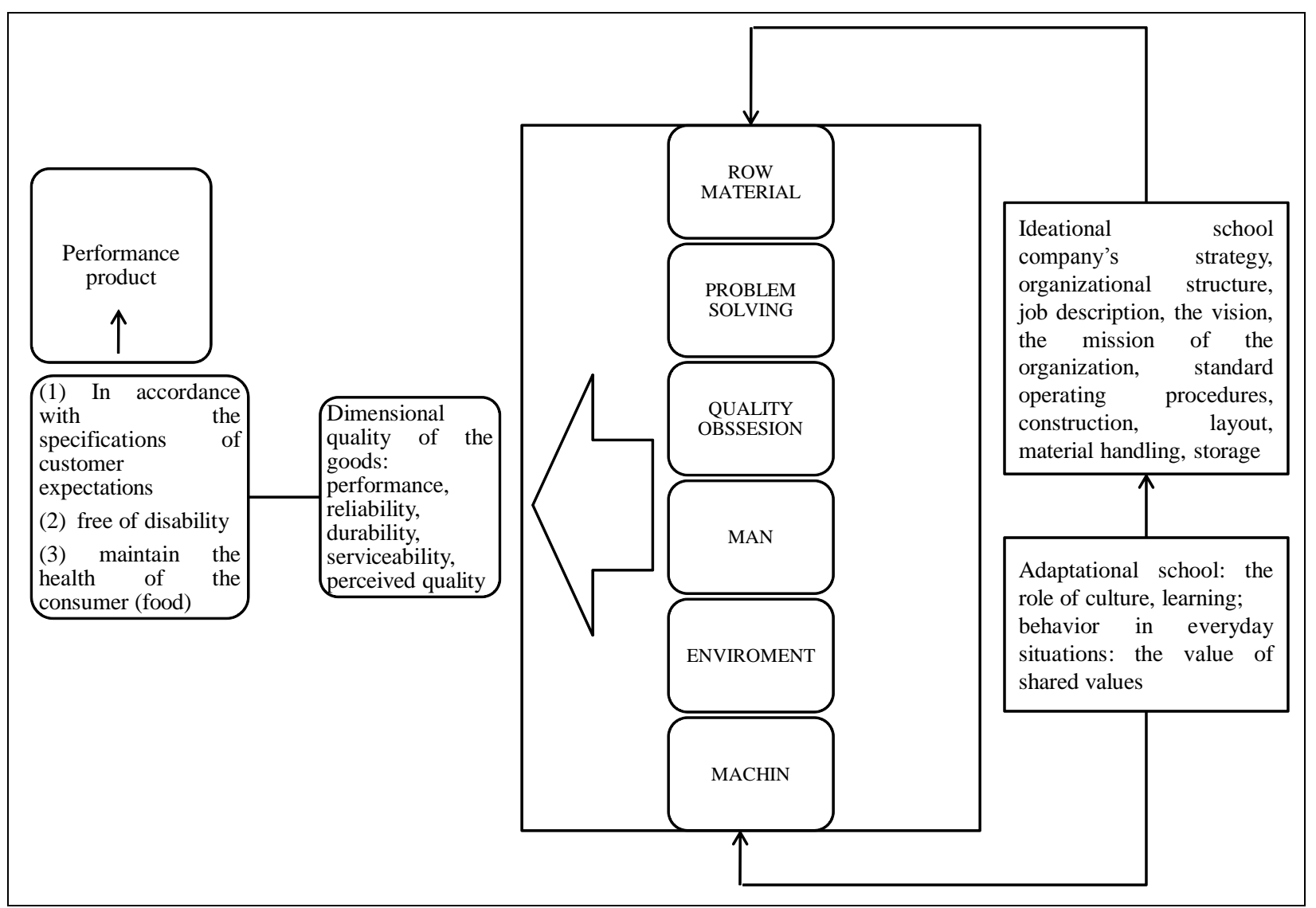

Figure 1. Quality culture model. 
Six dimensions that can be used as a model for measuring the quality of the company culture: (1) material handler; (2) handlers machines and production equipment; (3) artifacts/production environment; (4) human resources; (5) problem solving; and (6) obsession with quality, all of these dimensions related to trust, actions, mindset, values, habits, and thought, believed to be from the leader/employee/member organizations in the process of improving the performance, reliability, durability, serviceability, and perceived product continuously. The object of this study is that all the six dimensions of SMEs are adjusted to: (1) a material handler in the form of raw material; (2) handling process including the machine/tool; (3) handling of the final product; (4) labor; and (5) environment.

\section{Research Methods}

\section{Research Methodology}

This research uses qualitative research methods, with a grounded theory approach and case studies as the basis. Grounded theory according to Creswell (2009) is qualitative strategy in which the researcher derives general and abstract theory of a process, action, or interaction grounded in the views of participation in a study.

\section{Sample}

The sampling method is simple random sampling, where each SME randomly is selected and each of SMEs has an equal opportunity to be sampled. The number of SMEs of the sample was composed of 128, internal supply chain as many as 41 , samples upstream as many as 45 , and downstream samples as many as 42 .

\section{Results and Discussion}

\section{Supply Chain SMEs}

Based on the results of the study on 41 SMEs internal supply chain, involving 45 and 42 distributor or dealer upstream or downstream, supply chain sequence is obtained as follows.

Of $41 \mathrm{SMEs}$, none of them are directly related to industrial raw materials; they generally use either intermediate collectors, dealers, and suppliers. As with any industry cassava chips, it has not found that SMEs buy raw materials in the form of cassava from farmers. This condition shows that the main characteristics of the supply chain $100 \%$ of SMEs do not relate to the main processor but always through merchants, even carefully none related directly to the distributor or to the level two of the distribution of goods and services. From the field of analysis chips for industrial fish balls and cassava chips $80 \%$ to $90 \%$ of distribution sales made by the distributor, only $10 \%$ to $20 \%$ in selling directly to retailers and end customers, this was due to industry capacity chips fish balls and cassava chips already relatively large with the sequestration of cassava 2 to 3 ton/day/SMEs, while raw material for fish balls is about $600 \mathrm{~kg}$ up to 2 tons/day/SMEs. The uniqueness occurred in the industry, even though a large capacity, with the absorption of soybeans ranged between 2 quintals of up to 2 tons per day; almost $90 \%$ of its products are sold directly to the final consumer and the rest to retailers. This condition is caused, because the chips soy is a food that should be eaten right away and cannot be made safe.

Supply chain for fish and chips meatballs cassava chips, member upstream supply chain $90 \%$ owned by SMEs include cassava farmers, fishermen, craftsmen flour, chili farmer, chili milling industry, and collectors of firewood. The rest of the oil is controlled by big business form oil processing industry and palm oil distributor. For the industry supply chain, soy chips, scarf, and shirt industry, the main sources of raw materials, such as soybeans and textiles, are dominated by large businesses, such as soybean importer and textile industries with 
high technology. SMEs in this industry supply chain sequence play only adjuvant role in the sale of accessories, such as hoods, shirts, as well as firewood and baskets on soy chips. Because of the involvement of large businesses in the supply chain of industrial hoods, shirts, and soy crisps dominant, the tendency of this industry has a culture that is relatively better quality.

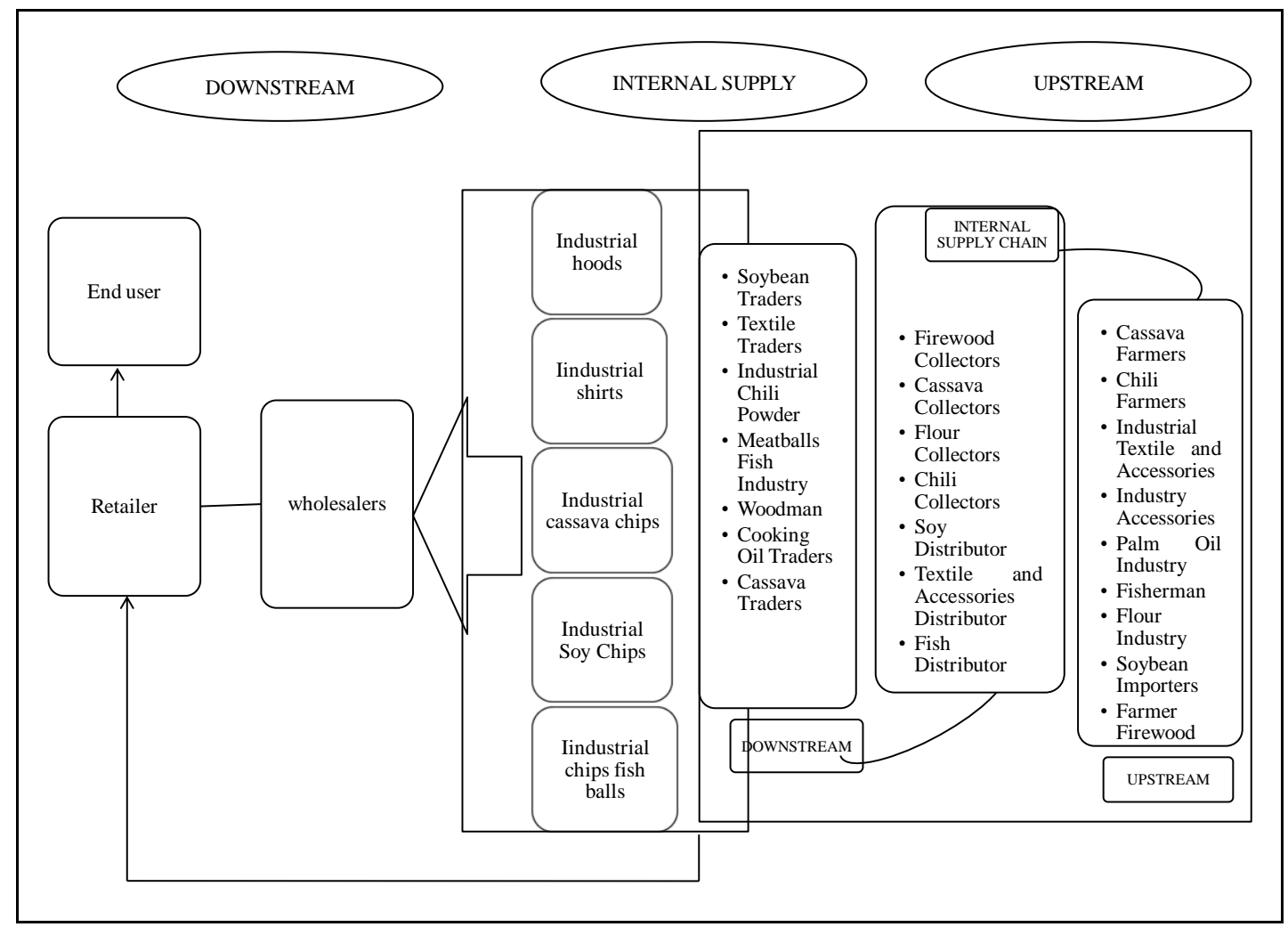

Figure 2. Supply chain SMEs.

\section{A culture of Quality in the Supply Chain of SMEs}

Measurement process quality culture uses Likert scale as the measurement scale with the size of the level one to five. Here is the average value of the implementation of a culture of quality in the supply chain coupling each industrial cluste.

Table 2

Quality Culture in Internal Supply Chain

\begin{tabular}{lllllll}
\hline Industrial cluster & Raw materials & Process & End process & Labour & Environment & Average \\
\hline Soy chips & 3.47125 & 3.735 & 3.72375 & 3.52875 & 3.8588 & 3.6635 \\
Chips fish balls & 3.18375 & 2.95875 & 2.81125 & 2.96 & 2.2325 & 2.82925 \\
Industrial shirts & 4.3375 & 4.6 & 4.515 & 3.9175 & 4.3225 & 4.3385 \\
Industrial hoods & 3.594 & 3.692 & 3.895 & 3.507 & 3.621 & 3.6618 \\
Cassava chips & 3.64 & 3.7 & 3.433333 & 3.4 & 2.715 & 3.64 \\
Average & 3.6453 & 3.73715 & 3.6756666 & 3.46265 & 3.35 & 3.62661 \\
\hline
\end{tabular}

Source: Compiled from field data, involving 45 SMEs.

From Table 2, it appears that the food processing industry in the form of chips and fish balls has cultural values which are very low quality category of 2.82925 or less well, while the highest value is on kaon industry 
cluster, with both categories. Industrial cluster soy chips and cassava chips are in the category of industrial hoods enough. The cultural dimension of the worst quality occurs in the work environment (3.35) kondidisi is visible once the field, where the scattered industrial equipment, plant layout, is not well ordered, the floor of the ground causes dust and dirty, the ceiling is dirty industrial buildings, storage material anywhere, etc. How is the condition of a culture of quality in the downstream and upstream of each cluster? The followings are presented in Table 3.

Table 3

Quality Culture Upstream and Downstream

\begin{tabular}{|c|c|c|c|c|c|c|c|c|}
\hline \multirow[b]{2}{*}{$\begin{array}{l}\text { Industrial } \\
\text { cluster }\end{array}$} & \multicolumn{4}{|c|}{ Upstream } & \multicolumn{4}{|c|}{ Downstream } \\
\hline & Material & Labour & Environment & Average & Material & Labour & Environment & Average \\
\hline $\begin{array}{l}\text { Soy chips } \\
\text { industry }\end{array}$ & 3.675 & 3.45 & 3.715 & 3.613 & 3.135 & 3.366 & 3.951667 & 3.48 \\
\hline $\begin{array}{l}\text { Industrial chips } \\
\text { fish balls }\end{array}$ & 2.938 & 2.92 & 2.486 & 2.781 & 2.9975 & 3.10 & 2.965 & 3.0208 \\
\hline Industrial shirts & 3.908 & 3.92 & 4.228 & 4.018 & 3.61 & 3.85 & 4.0025 & 3.820 \\
\hline Industrial hoods & 3.868571 & 2.94285 & 3.612857 & 3.473 & 3.802 & 3.4 & 3.768 & 3.656 \\
\hline $\begin{array}{l}\text { Industrial } \\
\text { cassava chips }\end{array}$ & 3.126 & 3.12307 & 2.503846 & 2.917 & 3.699 & 3.78 & 4.073 & 3.840 \\
\hline Average & 3.503 & 3.07 & 3.308 & 3.360 & 3.4486 & 3.499 & 3.751 & 3.5662 \\
\hline
\end{tabular}

Source: Compiled from a sample 42 downstream and 43 upstream sample.

Based on data in Table 3, it shows that the culture of the most excellent quality for the upstream supply chain occurs in a series of industry shirts (4.018). This is because $90 \%$ of businesses are large businesses that already have a standard equipment and technology sufficient to maintain quality. Likewise in the industrial processing of soy chips, it has a cultural value in the category of good quality. This happens because soy is a distributor of large businesses that already have standards, technologies, and procedures in the handling of raw soybeans. Seems to industries controlled by SMEs, such as fish balls chips, cassava chips have a culture of low quality, because they do not have the tools, technology, and quality standards with regard to handling, perceived quality, and working environment. How can a culture of quality in downstream conditions which appears in Table 3 above look almost flat in kagori enough? This happens because all of the actors in the distribution industry are SMEs that do not have standards, technology, and a good perception of quality care ward.

\section{Conclusions}

The analysis of the supply chain of SMEs indicates that during these, SMEs do not relate directly to the primary source of raw materials, such as textile soybean, cassava, chili, and fish balls. All they get from the merchant. These conditions result in a price other than the relatively more expensive, also resulted in a decrease in the quality of the product, because going through some of the industry or distributors with quality cultural diversity is different. when the upstream industry is big business both public and private, such as cooking oil, soybean importer, textile industry, they have a cultural value in the category of good quality (average 4.023), while if the role is small business, they have value average quality culture (2.458) included in the category of less good. To downstream, in the process of product distribution involving no big effort of SMEs, $100 \%$ are small businesses, so that the quality culture has considerable value in all clusters. Some things can be 
concluded relating to supply chain problems of SMEs and mapping the quality of upstream to downstream.

Problems occur in SMEs with poor quality of most major products in internal supply, especially in the food industry, because of the handlers of raw materials, processes, and materials. There is no provision either in writing Mapun or standardized. Generally, workers complete the work by habits that they see every day. If the final consumer can see firsthand the process of making cassava chips, soy chips, and chips fish balls, their tendency will decide not to consume, because the working environment work otor, smelling, dusty, and sometimes mixed with dirt. In general, SMEs do not yet have a good quality culture and the current culture of quality in the SMEs category average is still in the category enough (average 3.66), making it less able to support the ability to compete. To produce adequate product quality needs to be supported by a culture of quality in good company and therefore government intervention in supporting the establishment of a quality culture of SMEs is necessary, through training, counseling Mapun comparative study to companies that are very strict to retain the quality of the product.

\section{References}

Creswell, J. W. ( 2009). Reseach design, qualitative, quantitative, and mixed methods approaches. Los Angeles: Sage Publications Inc.

Croxton, K. L., Garcia-Dastugue, S. J., Lambert, D. M., \& Rogers, D. S. (2001). The supply chain management processes. The International Journal of Logistics Management, 12(2), 13-36.

Heizer, J., \& Render, B. (2010). Operational management. Jakarta: Salemba Empat.

Lambert, D. M., \& Cooper, M. C. (2000). Issues in supply chain management. Industrial Marketing Management, 29(1), 65-83.

Narasimhan, R., \& Kim, S. W. (2001). Information system utilization strategy for supply chain integration. Journal of Business Logistics, 22(2), 51-75.

Pujawan, I. N. (2005). Supply chain management. Surabaya: Guna Widya.

Seuring, S., \& Sarkis, J. (2008). An sustainability and supply chain management-An introduction to the special issue. Journal of Cleaner Production, 16(15), 1545-1551.

Spillan, J. E., McGinnis, M. A., Kara, A., \& Yi, G. L. (2013). A comparison of the effect of logistic strategy and logistics integration on firm competitiveness in the USA and China. The International Journal of Logistics Management, 24(2), 153-179.

Stank, T. P., Keller, S. B., \& Daugherty, P. J. (2001). Supply chain collaboration and logistical service performance. Journal of Business Logistics, 22(1), 29-48.

Tejaningrum, A. (2013). The effectiveness. The supply chain of soy chips industry. Proceedings from National Conference Entreprneur and Management, Maranatha University, Bandung, Indonesia.

Tejaningrum, A. (2014). Inconsistency quality products (on six sigma programs) effect on customer loyalty: Case study of industry “Tahu”. Journal of Management Study, 2(1), 35-42.

Tejaningrum, A., \& Anton Azis, I. (2015). Quality culture for SMEs model. Procceding from Internatioanl Conference Actual Economic, Local Solution for Global Challenges, Pattaya, Thailand.

Thomas, D. J., \& Griffin, P. M. (1996). Coordinated supply chain management. European Journal of Operational Research, 94(1), $1-15$.

Zhao, M., Cornelia, D., \& Theodore, P. S. (2001). The effects logistics capabilities on firm performance: Customer focused versus information focused capabilities. Journal of Business Logistics, 22(2), 91-107. 